\title{
Carlos II y el Papado: las negociaciones de una Liga de Italia contra Luis XIV (1674-1684)
}

\section{Charles II of Spain and the Papacy: the negotiations vis-à- vis a League of Italy in opposition to Louis XIV (1674-1684)}

\author{
María del Pilar Mesa Coronado \\ Investigadora independiente \\ mecomapil@gmail.com
}

Fecha de recepción: 29-04-2019

Fecha de aceptación: 01-08-2019

\section{RESUMEN}

El presente estudio se centra en uno de los factores esenciales de la política internacional de la Monarquía Hispánica en el Mediterráneo durante el reinado de Carlos II: la política expansionista de Luis XIV. La Monarquía Hispánica intentó mantener la presencia española en Italia frente a las tentativas de Luis XIV con el fin de evitar su alianza con la Santa Sede y los potentados italianos. De este modo, se analizarán las negociaciones que los embajadores españoles llevaron a cabo con el Papado para acordar una Liga de Italia contra el rey francés.

Palabras clave: Carlos II, Monarquía Hispánica, Papado, Liga, Luis XIV

Topónimos: Italia

Período: siglo XVII

\section{ABSTRACT}

This study is focused on one of the most important factors of the international policy of the Hispanic Monarchy in the Mediterranean during the reign of Charles II: the expansionist policy of Louis XIV. The Hispanic Monarchy attempted to maintain the Spanish presence in Italy during Louis XIV's expansionist undertakings with a view to preventing his alliance with the Holy See and the Italian Kingdoms. Thus, we will analyse the negotiations between Spanish ambassadors and the Papacy aimed at creating a League of Italy in opposition to the King of France.

Key words: Charles II, Hispanic Monarchy, Papacy, League, Louis XIV

Place names: Italy

Period: $17^{\text {th }}$ century 


\section{INTRODUCCIÓN}

La historiografía ha interpretado la segunda mitad del siglo XVII como un periodo en el que la Santa Sede afrontaba un proceso de debilidad política iniciado durante la Guerra de los Treinta Años y el pontificado de Urbano VIII. El Papado había ido perdiendo su capacidad de mediación en un contexto internacional marcado por la pugna hegemónica de la Monarquía Hispánica y la Corona de Francia. Su ausencia como garante de la firma de los tratados de Westfalia y de los Pirineos, confirmaba este proceso (Feldkamp, 2004: 61-63; Sella, 2003: 13-16). Sin embargo, estudios recientes como los de Maria Antonietta Visceglia recogen otra perspectiva bien diferente. La presencia en el seno del Papado de nepotistas y antinepotistas, caracterizada por sus intenciones reformadoras destinadas a potenciar el plano moral y a recuperar las finanzas, así como su interés de retomar el ideal de la Cruzada antiturca, ponen en duda la imagen de pasividad de la Santa Sede después del acuerdo de Westfalia (Visceglia, 2010: 43; Ochoa, 2006: 160 y 359; Barrio, 2009: 238239 y 2013).

Sin duda, la Santa Sede continuó concitando la atención diplomática de la Monarquía, pues a su función de cabeza de la Cristiandad, se sumaba su poder temporal en una parte de Italia. Su cercanía a los dominios italianos y la necesidad de la Corona de contar con su apoyo espiritual, político y económico, justificaron una representación diplomática acorde con la categoría del Papado.

No debemos olvidar que el reinado de Carlos II estuvo marcado por dos factores: la política expansionista de Luis XIV y el temor a la expansión otomana en el Mediterráneo. Respecto al primero, desde comienzos de la década de 1670, la política francesa se orientó a la recomposición de antiguas alianzas con el objetivo de erosionar las sólidas relaciones hispano-holandesas y desactivar cualquier acuerdo futuro como el logrado por la Triple Alianza. Sin embargo, en 1673 se acordaba en La Haya una nueva alianza entre Holanda, España, el Sacro Imperio y el ducado de Lorena. El acercamiento inglés a las posiciones holandesas, fraguado con la paz de Westminster de 1674, dejaba nuevamente aislada a Francia en un contexto internacional en el que la Monarquía Hispánica parecía incorporar a su causa a dos nuevos aliados (Sánchez, 1999: 157 y 165; Kamen, 2000: 219-221; Herrero, 2000: 375-376; Mitchell, 2016: 90-91)1.

Durante la guerra de Holanda, España debió atender tres frentes: los Países Bajos, Cataluña y el Mediterráneo. Fue en este último, donde cabe destacar la guerra de Mesina, que comenzó con una revuelta en julio de 1674 dando lugar posteriormente a una guerra, favorecida por el apoyo francés a los rebeldes mesineses en un claro intento por parte de Luis XIV de desestabilizar a la Monarquía Hispánica². Sin embargo, en 1678 se concretó la firma del tratado de paz de Nimega, por el que se ponía fin a la guerra de Holanda con la pérdida por parte española del Franco Condado, junto con una serie de ciudades en Flandes, además de la mitad de la isla de la Española (Kamen, 2000: 222-226).

La paz no duró mucho tiempo, ya que entre 1680 y 1683, se reactivó el interés expansionista de Francia a través de la política de las reuniones. Por ella, Luis XIV fue anexionándose nuevos territorios con el recurso constante a las cláusulas poco claras de los tratados de Münster y de Nimega. Francia sitió Luxemburgo y presionó a los Países Bajos españoles. Como consecuencia de ello, España declaró la guerra al monarca francés en diciembre de 1683. Sin embargo, el bombardeo francés de Luxemburgo, en 1684, y la falta

1 Sobre las relaciones diplomáticas de la Monarquía Hispánica durante la regencia de Mariana de Austria, véase Mitchell, 2019.

2 Para una visión completa de la revuelta de Mesina y posterior guerra, véase Ribot, 1982 y 2002. Sobre la política italiana del reinado de Carlos II, véase Alcalá-Zamora, 1976; y Zamora, 2013. 
de un apoyo específico por parte de sus posibles aliados llevarían a la Monarquía a pedir al emperador la defensa de sus intereses en Ratisbona. Por dicha paz, se acordaba una tregua de veinte años durante los que Francia conservaría la mayor parte de las poblaciones obtenidas con la política de "reunión" (Salvador, 2004: 239; Kamen, 2000: 229-230).

La política exterior de Carlos II continuó, por tanto, con la idea de la conservación de los dominios de la Monarquía Hispánica, tal y como había sucedido desde las paces de Westfalia y de los Pirineos. Había que defender la posición internacional de la Corona española, cumpliendo con la llamada política de prestigio o "reputación" para la que la mayor amenaza del momento era Luis XIV y sus aspiraciones de una "Monarquía Universal" (Storrs, 2012: 30-32). Ello se tradujo en toda una serie de medidas destinadas a potenciar la conservación, la paz y la estabilidad, dejando atrás la idea de nuevas conquistas territoriales.

La labor de los embajadores del monarca español contribuyó indiscutiblemente a la defensa y la supervivencia de la Monarquía, al tiempo que mantuvo un rol importante en la diplomacia de finales del siglo XVII (Storrs, 2012: 38 y 51; Yétano, 2011: 358). Un ejemplo de esta diplomacia fue el intento de acordar una Liga de Italia contra el monarca francés ${ }^{3}$. En este sentido, el presente artículo analiza dicho intento a través de las fuentes documentales sitas en el Archivo General de Simancas, el Archivo Histórico Nacional, el Archivo Secreto Vaticano y la Biblioteca Apostólica Vaticana4.

\section{LUIS XIV EN LA AGENDA DE LOS EMBAJADORES}

La política hegemónica de la Corona francesa, desplegada a raíz de las paces de Westfalia y los Pirineos, provocó el temor de la Santa Sede y enturbió sus relaciones diplomáticas. En 1662, el enfrentamiento entre las guardias del papa y las del embajador francés fue aprovechado por el soberano francés para reclamar una gran recompensa. La falta de ayuda de la Monarquía Hispánica confirmó al Papado que no podía contar con su apoyo, por lo que era necesaria una alianza duradera con el emperador. La desconfianza papal hacia Francia quedó evidenciada de nuevo con la pérdida de poder del "escuadrón volante", la reactivación de la facción española y la elección, en 1670, de Clemente X.

Posteriormente, la aprobación de los artículos "galicanos" (1682) en los que Luis XIV se convertía prácticamente en jefe de la Iglesia en sus dominios, despertó la oposición de la Santa Sede, propiciando su apoyo a la Liga de Augsburgo. La ruptura diplomática se produjo tras la encarcelación del nuncio en 1688 y la ocupación de los territorios papales en Francia, así como la plaza de Avignon y el ducado de Venaisis (Rivero, 2000: 153-154; Martínez, 2010: 636; Visceglia, 2004: 189).

En esta coyuntura, la política exterior de los pontífices presentó ciertas diferencias. El papa Clemente X (1670-1676) se caracterizó por una actitud excesivamente prudente en aspectos como la guerra de Holanda, donde su actuación no fue coherente. El éxito de los franceses significaba el restablecimiento de la libertad de culto de los católicos en países que eran protestantes desde hacía más de un siglo, pero exigía la renuncia papal a la defensa de las prerrogativas eclesiásticas en territorio francés, al tiempo que impedía que las potencias cristianas se unieran contra la amenaza turca.

La facción francesa habría obtenido el apoyo del pontífice, al menos hasta 1673, cuando a las dudas sobre las verdaderas intenciones de Luis XIV se sumaron la política

3 A lo largo de este artículo aparecerá mencionada la palabra Italia. Con ella, nos referimos al conjunto de reinos, repúblicas y ducados existentes en suelo italiano durante el siglo XVII, alejándonos, por tanto, del significado de Estado que adquirió con la Unificación Italiana.

4 Queremos advertir al lector que este artículo se centra principalmente en la opinión que la Monarquía Hispánica tenía sobre la política papal. No obstante, la visión de la Santa Sede aparece mencionada en algunos párrafos, gracias a las citas 7, 14, 22, 28, 29 y 34. 
regalista del soberano francés, así como las acciones diplomáticas de la Corona española y el Sacro Imperio. Desde ese momento, la Santa Sede concentró sus esfuerzos en la defensa de la Europa cristiana frente al Imperio Otomano (Osbat, 2000).

El papa Inocencio XI (1676-1689) tuvo que hacer frente igualmente a la amenaza turca y a la política expansionista de Luis XIV. Respecto a la primera, mantuvo desde el principio de su mandato la firme intención de acordar una liga contra la Sublime Puerta. En cuanto a la segunda cuestión, las relaciones diplomáticas con Francia no atravesaron su mejor momento. Al escaso papel concedido por esta al Papado en la paz de Nimega, se sumó la controversia del "galicanismo". A diferencia de su antecesor, Inocencio XI se opuso al soberano galo, lo que fue entendido por este como una provocación, llevándole a la publicación de los artículos "galicanos" (Menniti, 2000).

La política hegemónica de Luis XIV concitó, como hemos visto, la atención de la diplomacia europea de aquellos años. Por ello, no debemos olvidar que si se hubiera acordado una Liga de Italia, esta habría afectado al conjunto de las potencias italianas. Ahora bien, no todas ellas gozaron del mismo predicamento en la Corte madrileña, tal y como demuestran las instrucciones remitidas durante el reinado de Carlos II a los embajadores en Roma.

En opinión de la Corona española, el ducado de Saboya se había ido distanciando de los franceses, negándose a apoyar la invasión francesa de Génova al tiempo que suscribía la Liga de Augsburgo.

Los recelos de la Corte madrileña hacia el ducado de Módena no se aplacaron hasta que Laura Martinozzi, esposa de Alfonso IV, consiguió que Francisco II solicitase la protección española y se alejase de Luis XIV.

Mientras tanto, el Gran Ducado de la Toscana, que había intentado mantener una posición neutral, comenzó a apartarse del monarca galo debido a la turbulenta relación del duque Cosme III con su esposa, Margarita Luisa de Orleans, prima de aquel. En consecuencia, el duque concertó los matrimonios de sus hijos con aliados del monarca español y el emperador.

Por su parte, la República de Génova, aliada tradicional de la Corona española, mantuvo buenas relaciones con esta hasta el bombardeo francés de 1684, cuando se vio obligada a firmar un acuerdo con Francia que le imponía el desarme de la escuadra genovesa y la petición del perdón francés.

Pese a todo, los territorios más problemáticos de Italia fueron los ducados de Mantua y Parma, así como la República de Venecia. Las sospechas sobre Mantua surgieron por la decisión del duque de entregar la plaza de Casale -bajo dominio español- a Francia. Por su parte, la desconfianza hacia el ducado de Parma apareció cuando este perdió el estado de Castro a manos de la Santa Sede, motivando el temor a una alianza entre parmesanos y franceses en la que estos últimos facilitasen la devolución de dicho territorio.

Por último, la República de Venecia fue vista por la Corona española como una potencia guiada por la consecución de sus propios intereses, sin importarle si ello afectaba al resto de la Cristiandad. Durante la guerra de Mesina permitió la extracción de suministros de sus dominios para socorrer la ciudad rebelde, impidió el traslado de los refuerzos alemanes proporcionados por el Sacro Imperio y toleró la presencia de embarcaciones francesas en sus aguas. Asimismo, negó su apoyo a la Liga de Italia contra Luis XIV, pues temió la reacción de una Francia cada vez más poderosa frente a una Monarquía Hispánica cada vez más debilitada (Mesa, 2017: 261-273).

Es en este contexto internacional en el que la seguridad del Mediterráneo se resquebrajó con el estallido en 1674 de la revuelta de Mesina que, apoyada por Luis XIV, marcó un giro en la diplomacia de la Monarquía con la Santa Sede y con las potencias de Italia. La Corona 
española solicitó sin éxito la asistencia de las escuadras de la Santa Sede, la República de San Marcos y el ducado de Toscana (Marqués, 1982-1983: 201). Por su parte, el pontífice negó el socorro alegando su obligación de mantenerse neutral como Padre Común de la Cristiandad. En diciembre, Mariana de Austria ordenaba a los virreyes, embajadores y gobernadores en Italia que indagasen la posición de los príncipes italianos frente a una liga que, con el pretexto de crearse contra el "enemigo común", tendría por enemigo a Luis $\mathrm{XIV}^{5}$. Una vez más, el Papado rechazaba la propuesta española, por lo que se confirmaba -según el cardenal Nithard- que el único fin que movía al papa y sus ministros era:

[...] gozar de la quietud acumulando riquezas a sus Nepotes, de que es buena prueva haver negado sus Galeras para Mesina en el principio de aquellos accidentes [...] y respondiéndole en términos generales de ningún fundamento a la propossición que hico a Su Santidad $[\ldots]^{6}$.

El cardenal no podía ocultar su enfado al comprobar la parcialidad del papa en sus intervenciones. El embajador había sido informado del permiso otorgado por el pontífice para la extracción de víveres y municiones destinados al "fomento de la rebelión". De hecho, Pedro de Aragón había protestado ante el nuncio por las noticias que le habían llegado referentes a tres naves cargadas de trigo que tenían previsto partir hacia Mesina. El nuncio desmentía que dicha información fuera cierta, mientras el pontífice sostenía que su decisión de no asistir a la Corona con su escuadra procedía de sus ministros, algunos de ellos vinculados a Francia (Dandelet, 2002: 258) ${ }^{7}$.

Los años siguientes se caracterizaron por una reactivación de las negociaciones con la Santa Sede para la constitución de una liga italiana, al tiempo que el Papado fijaba su objetivo en una unión de las potencias cristianas contra los otomanos. En este sentido, desde 1676 se reclamó a la Monarquía Hispánica su contribución económica en conflictos como el que enfrentaba a Polonia con el Imperio Otomano. La intención era destinar la mitad de lo que se recaudaba con la décima eclesiástica en los dominios italianos a dicha guerra y evitar de esta forma que los polacos firmasen la paz (Marqués 1982-1983: 67) ${ }^{8}$.

Los esfuerzos de la Monarquía Hispánica, empero, parecían más encaminados a demostrar los verdaderos fines del soberano francés, con el fin de propiciar la reactivación de las negociaciones para la liga italiana. A finales de 1676, el cardenal Nithard había asegurado al papa que Luis XIV había persuadido al rey polaco para acordar la paz con los otomanos, pues no existía ninguna otra razón que explicase su decisión. El Consejo de Estado apoyó la actuación del cardenal ordenándole que se valiese del contexto internacional para convencer al pontífice de que Francia era uno de los beneficiarios del acuerdo. Si la Sublime Puerta quedaba liberada del frente polaco, concentraría sus fuerzas en Hungría obligando al emperador a retirar las suyas de Alsacia, lo que permitiría a su vez al monarca francés centrar sus objetivos en los territorios italianos. Por ello, debía recomendarle su intercesión en una paz que frenase aquellos deseos expansionistas. Poco después, Nithard comunicó al papa que el soberano francés había contratado parte de las tropas licenciadas por el rey polaco para potenciar la rebelión en Hungría. A continuación,

5 Archivo General de Simancas (en adelante AGS), Estado (en adelante E), leg. 3.514, doc. 55, leg. 3.048, docs. Nápoles, 31-08-1674 y Madrid, 03-10-1674.

6 AGS, E, leg. 3.049, doc. Madrid, 14-03-1675.

7 Archivio Segreto Vaticano (en adelante ASV), Archivio della Nunziatura di Madrid (en adelante ANM), leg. 16, fol. 122; AGS, E, leg. 3.049, doc. Madrid, 22-03-1675.

8 AGS, E, leg. 3.051, docs. Roma, 02-05-1676 y Madrid, 10-06-1676. 
le instó a una liga italiana, aunque la respuesta fue otra vez negativa excusándose en que dicha medida provocaría el enojo del francés y su rechazo a una paz ${ }^{9}$.

\section{3. ¿UNA NUEVA LIGA DE ITALIA?}

\subsection{Primeras negociaciones}

Con la llegada del nuevo embajador, Gaspar de Haro y Guzmán, marqués del Carpio, el soberano español hizo balance de la situación que atravesaban las negociaciones. En 1674, la coyuntura política marcada por la conquista otomana de Candía y el estallido de la revuelta de Mesina, fomentada por la Corona francesa, motivó la propuesta de una liga defensiva de los príncipes italianos que, con el pretexto de crearse contra el sultán, tendría por enemigo a Luis XIV. Se iniciaron entonces las pesquisas destinadas a valorar los posibles apoyos a este proyecto, pero no darían su fruto. El cardenal Nithard, el príncipe de Ligne, el conde de Benazuza y del marqués de Villagarcía afirmaban que sus investigaciones no habían tenido éxito. Según la inteligencia de la Corona el pontífice no era partidario de una liga que pudiera alterar la quietud de sus posesiones; la República de Venecia no quería enturbiar sus relaciones con Francia y que esta pudiera enemistarla con los otomanos; el Gran Duque de la Toscana se apartaba de la proposición; el duque de Saboya temía por su vecindad con Francia; el de Parma también era partidario de Luis XIV; y el duque de Módena no mostraba con claridad sus intenciones. El duque de Mantua se manifestaba a favor siempre y cuando se organizara un frente común con otros príncipes italianos; y por último, Génova era partidaria de mantener el statu quo en la zona. El Consejo de Estado fue consciente de la dificultad de la propuesta porque los príncipes de Italia temían el poder que estaba adquiriendo Luis XIV y, por tanto, las consecuencias negativas de una alianza con España. Por ello, las indagaciones quedaron suspendidas hasta que una coyuntura más favorable permitiese retomar las negociaciones (Marqués 1982-1983: 201; Signorotto, 2007: 590) $)^{10}$.

Siguiendo el informe real, poco después tuvo lugar el incidente con la República de San Marcos en el golfo de Venecia. En marzo de 1675, los venecianos habían impedido el traslado de las tropas alemanas del regimiento del conde Porcia que, embarcadas en Trieste, tenían como destino Pescara para ser transportadas como asistencia para la guerra de Mesina. La Monarquía Hispánica, apoyada por el emperador y la República holandesa, había pedido la satisfacción de la República de Venecia. Sin embargo, esta última se había valido del paso del tiempo para no cumplirla, obligando a la Corona a excluirla como mediadora en el tratado de paz entre Francia y España. Posteriormente, el cardenal Nithard había informado de las nuevas intenciones de la república. Los cardenales Basadona y Ottoboni habían encargado a un antiguo general de los franciscanos, Francisco María de Cremona, que le comunicase el posible cambio de opinión de Venecia. Ahora, que el mayor problema de Europa era Luis XIV, consideraba esencial la firma de una liga italiana que lo frenase porque si conquistaba Sicilia se convertiría en la mayor amenaza de los territorios italianos. Por su parte, Nithard, consciente de que los dos cardenales no habían actuado en base a una orden de la república; creía, sin embargo, que estaba informada de todo, por lo que veía factible retomar el asunto con la Santa Sede (Ribot, 2002: 191-194) ${ }^{11}$.

El marqués de los Vélez había hablado también con el cardenal Basadona sobre la conveniencia de establecer primero la paz en Italia mediante una liga entre la Corona

9 AGS, E, leg. 3.053, docs. Madrid, 10-01-1677 y Madrid, 10-02-1677.

10 AGS, E, leg. 3.049, docs. Madrid, 14-03-1675; leg. 3.192, doc. Buen Retiro, 19-02-1677. Sobre Gaspar de Haro y Guzmán, VII marqués del Carpio y Heliche, véase Ramírez, 1927: 34-37; Herrero, 2009.

11 AGS, E, leg. 3.192, doc. Buen Retiro, 19-02-1677. 
española y la República veneciana. De este modo, se decidió que el cardenal Nithard reavivase las negociaciones con el Papado para una liga que podía facilitar la conclusión de la paz general. No obstante, el pontífice aseveraba que el cardenal Basadona no le había propuesto nada, aunque de todas formas, no era la mejor opción en aquellas circunstancias, porque obstaculizaba una paz con el rey francés en el norte de Europa. Para el Papado, era más importante la intervención de la Serenísima como mediadora en la paz entre Francia y España. Por ello, el emperador determinó que fuese el papa quien decidiese la forma de satisfacción con la que la república pondría fin al asunto del golfo. El nuncio sostenía que el pontífice tenía la intención de pedir como obsequio, por su designación como papa, que el soberano español diese por zanjado el tema. Al parecer, alegaba que los venecianos no aceptarían una satisfacción similar al agravio y una de calidad inferior resultaba deshonrosa para el monarca español (Marqués 1982-1983: 200). El informe real terminaba ordenando al marqués del Carpio que con esta información retomase la propuesta con la Santa Sede y la República de Venecia ${ }^{12}$.

Las gestiones del marqués del Carpio comenzaron con mal pie. El pontífice le había pedido que le informase sobre las novedades de la cuestión veneciana. El marqués le había confirmado la intención de exonerar a la república a cambio de que Su Santidad formase parte de una liga, que incluiría a la Monarquía Hispánica y a la República de San Marcos contra el gran turco y todo aquel que quisiera invadir Italia. El papa, enojado con la propuesta, se negó a aceptarla porque la participación de los venecianos comprometía su mediación en la paz general. El marqués replicó que dicha unión no cuestionaba la neutralidad de nadie, al tiempo que era la condición sine qua non para dar por solventada la disputa del golfo (Marqués 1982-1983: 200) ${ }^{13}$.

Por su parte, el marqués de los Vélez comunicaba que le había llegado el rumor de la escasa estima que el pontífice parecía tener al embajador español. Añadía además, que el cardenal Cibo se hallaba con la esperanza de que Juan José de Austria lo sancionase, lo que le permitía reiterar que todo este asunto había sido tramado entre el pontífice, el cardenal Cibo y el duque d'Estrées, embajador de Francia. Asimismo, se refería a la actitud profrancesa del Papado, que continuaba asistiendo con trigo a la rebelde Mesina, había puesto Civitavecchia a disposición de la armada de Luis XIV y el estado de Branchano bajo control del embajador francés, aunque el nuncio seguía desmintiendo aquellos hechos. De nada estaban sirviendo las protestas de la Corona española. Estaba claro que esta última se estaba viendo claramente afectada por el uso indebido de aquel puerto por parte de los franceses como refugio y lugar desde el que impedir el comercio de Sicilia y proteger a los rebeldes de Mesina y a las fuerzas del gran turco. Por ello, Carlos II ordenaría a su embajador que continuara insistiendo ante la Santa Sede para que las galeras francesas abandonasen los puertos pontificios ${ }^{14}$.

La falta de éxito y las diferencias con la Santa Sede no desanimaron a la Corona española. En un memorial, Carlos II planteaba la coyuntura política, marcada por la amenaza de Luis XIV al ducado de Milán y la posibilidad de un ataque turco a Italia. El único remedio pasaba por una liga defensiva que uniera a todos los estados y repúblicas italianos contra cualquier potencia que perturbase la tranquilidad de Italia. Para ello, solicitaba que el pontífice formase parte de ella y la promoviese ${ }^{15}$.

12 Ibídem; E, leg. 3.053, docs. Roma, 20-02-1677 y Madrid, 29-05-1677.

13 AGS, E, leg. 3.053, docs. Roma, 15-05-1677 y Madrid, 15-06-1677.

14 Ibídem; ASV, ANM, leg. 16, fol. 111; leg. 42, f. 170.

15 AGS, E, leg. 3.056, doc. Madrid, 24-12-1677. 
A comienzos del año siguiente, el marqués del Carpio volvió a plantear la propuesta valiéndose de los intentos del soberano francés para potenciar la rebelión de Hungría contra el emperador. No obstante, Inocencio XI la desechó alegando que la noticia de la adhesión papal a una confederación contra el sultán, lo enojaría y motivaría la reanudación de sus movimientos ahora que habían desaparecido los temores a una invasión en Ragusa. Añadía además, que no entraría en una confederación que le enemistase con el soberano francés impidiéndole participar como mediador en la paz general. Esta última debía ser -según el papa- la prioridad de la Corona española, ya que constituía la única forma de acabar con los conflictos en Hungría ${ }^{16}$.

La rebelión de Hungría aludida en las negociaciones era el movimiento antihabsburgo y anticatólico de Nicola Zrinyi e Imre Thököly que reivindicaba un reino de Hungría independiente, sin intervención de Viena, aunque reconociendo su condición de vasallo del Imperio Otomano. La situación, como veremos a lo largo de estas páginas, continuó siendo problemática, pues en 1682, Mehmet IV reconoció como rey de Hungría a Thököly mientras los rebeldes se hacían con la Alta Hungría Imperial. La rebelión sería aprovechada por Luis XIV para debilitar a los Habsburgo, quienes habían firmado la Liga de Augsburgo, al tiempo que Thököly se unía al príncipe transilvano Miguel I Apafi y a la Sublime Puerta. En 1683, Thököly conquistaba la Alta Hungría y el gran visir Kara Mustafá, el pachá de Buda y el kan de los tártaros avanzaban por el Danubio con unos 100.000 efectivos con el objetivo de conquistar Viena (González, 2012: 223-224).

El marqués del Carpio, mientras tanto, lo volvería a intentar sin resultado alguno. En esta ocasión, el pontífice alegó toda una serie de excusas: la posibilidad de reactivación del peligro turco con dicha propuesta; la negativa de la República veneciana a participar porque temía la reacción del sultán; el recurso de la Santa Sede a otros medios para frenar la amenaza otomana; el entredicho al que se vería abocada la neutralidad papal por la aceptación de dicho acuerdo; la inexistencia de un verdadero recelo a un ataque francés en Milán; y la difícil situación que atravesaba la hacienda pontificia. Ante tal panorama, el Consejo de Estado acordó detener las negociaciones hasta que llegase a Roma el embajador extraordinario, el cardenal Portocarrero, que actuaría en calidad de embajador extraordinario (Marqués, 1982-1983: 202)17.

El rey ordenó al cardenal Portocarrero emplear el argumento del fin de la guerra de Mesina para impulsar la liga. Según el soberano, el temor a las armas francesas y su empleo en Sicilia ya no podían justificar la renuencia del pontífice. Ese mismo mes, el pontífice le recriminó al marqués del Carpio la escasa atención de la Corona española a la paz general culpándola de los continuos retrasos en su ejecución. El embajador contestó que ningún otro gobernante tenía más interés en mantener la calma de la Cristiandad como se demostraba con su intención de lograr una unión en territorio italiano. Algo que volvería a reiterar cuando el papa le pidió que escribiese a los virreyes de Nápoles y de Sicilia para solicitarles su asistencia a la República de Ragusa, amenazada por el sultán. Para el marqués, lo único que liberaría a Italia del peligro al que se exponía con la hipotética conquista de Ragusa era la creación de una liga ${ }^{18}$.

Pese a ello, las cartas del marqués del Carpio y del Cardenal Portocarrero hacían hincapié en el desinterés por la liga. El marqués era consciente del deseo real de una intercesión imperial a favor de esta causa, pero no la veía plausible porque el emperador podía granjearse la enemistad de Francia y con ella, la posibilidad del apoyo francés a

16 AGS, E, leg. 3.056, docs. Roma, 06-02-1678 y Madrid, 12-03-1678.

17 AGS, E, leg. 3.056, docs. Roma, 23-01-1678 y Madrid, 27-02-1678; leg. 3.567, doc. 92. Sobre el cardenal Luis Manuel Fernández de Portocarrero y Guzmán véase en Sanz, 2009; Peña, 2004.

18 AGS, E, leg. 3.057, doc. Aranjuez, 01-05-1678, leg. 3.302, docs. 208 y 209. 
los planes del sultán. En su opinión, no se debía insistir tampoco con los potentados de Italia porque alegaban cualquier excusa para no firmarla provocando a su vez la negativa papal. Resultaba más conveniente centrarse en el apoyo de la Santa Sede a la cuestión y obtener así la participación del resto de las potencias. Para ello, consideraba que el más preparado era el cardenal Portocarrero, aunque no ocultaba que incluso con él continuarían las excusas y las dificultades (Signorotto, 2007: 590) ${ }^{19}$.

El cardenal, por su parte, confirmó los malos presagios del embajador. Explicó a Su Santidad que su misión era solicitar que promoviese la idea del soberano español de una liga defensiva contra el gran turco con el propósito de liberar a la Cristiandad de la amenaza que se cernía sobre Ragusa. Su estrategia de no mencionar a la Corona francesa reservando este punto para una futura negociación, resultó un fracaso. Inocencio XI reiteró sus anteriores respuestas. Señaló además, que la argucia de ocultar el nombre de Francia no escondía que se trataba de una unión contra ella. El pontífice mantenía que la Santa Sede ayudaría a contrarrestar una supuesta invasión turca en Italia o Malta solicitando el socorro de las potencias cristianas, pero no a través de una liga. Lo más apropiado era una pequeña unión de recursos económicos y navales como los que se aportaron en Candía, por lo que recomendaba a Carlos II que preparase sus galeras para unirlas a las de la Santa Sede, Orden de Malta, Gran Ducado de Toscana y la República de Génova en la lucha contra los otomanos ${ }^{20}$.

Unos días después, el pontífice se refirió a la guerra contra el turco y a su petición al soberano polaco para que no ratificase la paz del sultán y se opusiera a él como lo hacía la República de Ragusa. Aprovechando la oportunidad que le brindaba este tema, el cardenal planteó de nuevo la posibilidad de crear una liga contra los otomanos, pero el papa respondió que dicha medida era improcedente porque lo importante en aquellos momentos era la paz general. El Consejo de Estado resolvió a favor de suspender sus acciones y reclamar su retorno a España, dejando la cuestión en manos del marqués del Carpio ${ }^{21}$.

Inocencio XI mostraba sólo interés por la paz entre la Monarquía Hispánica y Francia. Concluido el conflicto, los dos combatientes podrían contribuir en la defensa del reino de Polonia. Su soberano se hallaba en la difícil tesitura de ratificar la paz firmada con la Sublime Puerta, pero la Santa Sede le había prometido la ayuda de las potencias cristianas. Por este motivo, el nuncio, en cumplimiento de la orden papal, solicitaba a Carlos II el aumento y disposición de las fuerzas marítimas de sus dominios italianos, socorriendo a su vez a Ragusa con el propósito de distraer al Imperio Otomano de Hungría y Polonia, porque si esta última y Rusia se rendían, el sultán dirigiría su hostilidad hacia Hungría y la zona italiana. De este modo, la colaboración española serviría a un doble fin: la defensa común de la Cristiandad y la protección de sus reinos de Nápoles y Sicilia, principal objetivo del Imperio Otomano 22 .

\subsection{Una liga contra el turco}

En octubre de 1678, el papa se mostraba más esperanzado porque Luis XIV y Carlos II habían firmado el tratado de Nimega y las hostilidades entre rusos y otomanos seguían activas, por lo que Hungría e Italia quedaban libres de peligro. Ahora bien, la amenaza no

19 AGS, E, leg. 3.057, doc. Madrid, 30-06-1678.

20 AGS, E, leg. 3.057, doc. Roma, 29-05-1678. Sobre las relaciones entre la Monarquía Hispánica, la República de Venecia y la Santa Sede durante la guerra de Candía, véase Quiles, 2018; Mesa, 2014 y Andretta, 1998.

21 AGS, E, leg. 3.058, docs. Roma, 13-06-1678, Madrid, 20-07-1678, Roma, 21-08-1678, Roma, 21-08-1678 y Madrid, 22-09-1678.

22 ASV, ANM, leg. 10, fols. 533-534; AGS, E, leg. 3.058, doc. Madrid, 27-08-1678. 
había desaparecido y el Papado insistía en aprovechar la paz para unirse contra el sultán. El marqués del Carpio, sin indicaciones de la Corte, sostuvo que el soberano español cooperaría con la Santa Sede, pero se le debía garantizar la contribución del monarca francés, pues las noticias parecían confirmar lo contrario. Se sospechaba que Luis XIV había sobornado al sultán para incitarlo a la guerra contra el emperador, aunque Inocencio XI lo negaba (Fernández, 2009: 267) ${ }^{23}$.

Aprovechando la paz de Nimega, el embajador pidió audiencia al Papado y argumentó que se desencadenaría contra Italia y Hungría la invasión otomana si el sultán se liberaba de sus conflictos con Polonia y Rusia. A continuación, urgió a Su Santidad a promover una liga contra el "enemigo común" o cualquier otro que intentase invadir los territorios italianos. Por último, mencionó que el soberano francés no sospecharía nada, pues el abandono de Mesina había demostrado su aparente desinterés por los dominios italianos ${ }^{24}$.

La única forma de conseguir lo que pretendía Carlos II pasaba por aumentar sus fuerzas marítimas y unirlas a las de la Santa Sede, Toscana, Génova, la Orden de Malta e, incluso, a las de Venecia, si esta última lo consideraba oportuno. Los gobernantes italianos -según el pontífice- temían por igual la presencia del sultán y de Luis XIV en Italia, pero no se declararían a favor de la Monarquía Hispánica hasta que fuera capaz de suministrar un número eficaz de fuerzas. Cuando se garantizase esta condición le apoyarían contra el Imperio Otomano e, incluso contra el monarca francés. No obstante, aconsejaba mantener aquella reunión en secreto por la gravedad del asunto tratado.

Asimismo, le comunicó la solicitud que había dirigido al obispo de Heliópolis para que instase a Luis XIV a participar en la defensa de la Cristiandad frente al sultán y a ratificar la paz con España. Con ello, pretendía impedir la expansión del sultán, no por "vanidad, ni lograr en su tiempo lo que otros Pontífices no pudieren conseguir en el suyo, sino sólo cumplir en la obligación que Dios le havía puesto y tener menos quenta que darle quando fuese llamado a su Presencia". Todo parece indicar que era consciente de que su comportamiento podía entenderse como un exceso de permisividad hacia Francia, pero en realidad era su condición de Padre Común la que le obligaba a tomar ciertas decisiones de las que no se sentía orgulloso 25 :

No puedo declararme quanto quisiera, pero me persuado que tiene penetrado lo que oculto sin que sea necesario referírselo. Si le parece, como buen Ministro del Rey Cathólico, que tenemos cerrados los ojos a las cosas de Franceses, no dejará de tener razón, pero créame que el tenerlos muy abiertos hace que los cerremos en muchas cosas, siendo fijo que si el señor Don Juan (que es hermano del Rey, Dios le guarde, y su primer Ministro) se hallase sentado en esta silla, como lo estoy yo indignamente, no sólo obraría lo que yo, sino quizá con más contemplación, pues somos Padre Común y devemos procurar en el conflito, en que oy nos hallamos, no hacer lo mejor sino lo menos malo, por no dar en algún precipicio grande [...]

La insistencia del marqués a Inocencio XI con la creación de una liga defensiva, llevó al pontífice a mostrar su malestar por el incumplimiento de sus consejos. Desde sus tiempos de cardenal, había advertido a los embajadores del rey español la urgencia de mejorar los presidios, fortificar las plazas y aumentar las galeras en Italia, fundamentos sobre los que organizar una liga. Sin embargo, había comprobado cómo la Corona española había

23 AGS, E, leg. 3.059, doc. Roma, 02-10-1678.

24 AGS, E, leg. 3.059, doc. Madrid, 03-12-1678. Sobre la influencia francesa en las decisiones papales, véase Poncet, 2011.

25 Ibídem. 
aumentado su presión sobre el Papado mientras ignoraba la debilidad de sus fuerzas, lo que a su vez redundaba en la desconfianza de los príncipes de Italia en una unión con la Monarquía Hispánica favoreciendo un hipotético ataque francés u otomano. Con este panorama era comprensible que ningún territorio italiano quisiera aliarse con los españoles, pues comprometían su futuro. Por su parte, continuaría intentando convencer al monarca francés para que abandonase sus designios expansionistas, pero lo consideraba francamente difícil debido a la ambición desmedida de Luis XIV. El embajador veía en estas palabras la confirmación del miedo del Papado al anterior. El pontífice no firmaría un pacto de estas características ni siquiera cuando el monarca francés entrase en Italia, porque su temor no desaparecía con simples palabras ${ }^{26}$.

Sin embargo, por orden del Consejo de Estado, el marqués continuaría instando a la Santa Sede a la liga italiana, como hizo con el cardenal Cibo. Este último le contestó que no entendía con quién pretendía concertar dicha unión, pues los venecianos no se hallaban interesados, los genoveses temían al rey francés, el ducado de Saboya había pactado con él, Parma vigilaba los movimientos de Luis XIV para anexionarse la ciudad de Castro, el ducado de Módena estaba inmerso en las reclamaciones de Ferrara y el duque de Toscana no se había pronunciado en ningún sentido. Aunque el pontífice estuviera de acuerdo con el negocio se vería impedido por la falta de apoyo de los gobernantes italianos, pero se consideraba un pacto innecesario, porque el Papado tenía la certeza de que Francia no perturbaría Italia. Pese a los intentos del marqués, el Consejo de Estado estuvo de acuerdo en suspender la propuesta. La solicitud papal a las potencias cristianas de unirse en una liga contra el "enemigo común" confirmó las escasas posibilidades de esta materia, obligando al Consejo a emitir instrucciones a todos sus representantes en suelo italiano para que no volvieran a tratar el asunto 27.

El arzobispo de Cesárea, nuncio de Su Santidad, comunicó a Carlos II que el deseo de Inocencio XI de una paz entre Francia y la Monarquía Hispánica, tenía por objetivo acabar con una guerra que estaba obstaculizando la lucha contra el turco y, por tanto, favoreciendo su expansión por Europa. Una vez firmado el tratado de Nimega, se podía conseguir el anhelo de "unir a los Príncipes reconciliados en una sagrada conspiración contra la insolencia del Turco, el qual siempre más sediento de la sangre christiana y ansioso de nuestras ruinas, no cessa de amenaçar Ytalia...". De este modo, el papa había enviado un breve a Carlos II, Leopoldo I, Luis XIV, Juan Sobieski y a la República de San Marcos, entre otros, instándoles a unirse en defensa del "bien común y de la Cristiandad". Esta proposición -según el pontífice- debía interesar especialmente a Carlos II, pues se trataba de un enemigo "que no puede acometer a Ytalia sin endereçar los primeros golpes de su insaciable furor contra los estados que Vuestra Magestad posee en ella...28".

En palabras del papa, era una oportunidad que no podía desaprovecharse, porque las tropas de las potencias católicas se hallaban habituadas a la guerra e, incluso, se esperaba un pacto antiturco entre Rusia y Polonia. Inocencio XI rescataba la antigua idea de "Cruzada" gracias a la sugerencia del capuchino francés Paul de Lagny, pero con un significado más político que religioso. Atrás quedaba el viejo anhelo de reconquistar Jerusalén empleando la lucha contra los infieles para conseguir el objetivo de la Iglesia de salvar la humanidad restaurando el reino de Dios en la Tierra. Ahora, el propósito se resumía en una guerra contra el gran turco para alejarlo definitivamente de Europa. Con todo, detrás de esta nueva

26 AGS, E, leg. 3.057, doc. Madrid, 23-04-1679.

27 AGS, E, leg. 3.060, docs. Roma, 30-04-1679, Madrid, 05-06-1679 y Madrid, 05-06-1679.

28 AGS, E, leg. 3.060, doc. "Tradución del memorial con que el Nuncio de el Papa acompañó al Breve de Su Santidad de 19 Marzo 1679 que presentó a Su Magestad". 
concepción, parecía reafirmarse el deseo del pontífice de recuperar el antiguo poder de la Santa Sede. Al igual que sus antecesores del Renacimiento, optó por la "Cruzada" como un instrumento que le garantizaba su papel de cabeza de la Cristiandad y de dirigente de los gobernantes seculares (Tamborra, 1961: 8; Rivero, 2008: 20 y 30; Platania, 1998: 253 y 259; Palacios, 2015; Poumarède, 2011: 146-147 y 151-152) ${ }^{29}$.

El Consejo de Estado examinó a fondo la petición y asesoró a Carlos II en su respuesta al pontífice, tal y como defendía el condestable de Castilla, que apreciaba la recomendación papal porque seguía la línea de la antigua propuesta de la Monarquía Hispánica, pero sospechaba que todo era fruto de una argucia francesa para despistar al pontífice de sus preparativos para invadir Italia. Pese a ello, recomendaba aceptarla para que no se cuestionase la condición católica del soberano, aunque resultaba conveniente solicitar algunos detalles de la liga, tales como: las potencias que habían confirmado su participación; los contingentes militares que aportarían; las operaciones que se desarrollarían, y si estas debían contar con el acuerdo de todos los participantes, así como los ejércitos y fuerzas marítimas que se emplearían. Sin embargo, no sirvió de nada porque el nuncio se limitó a contestar en nombre de Inocencio XI a Pedro de Aragón con un agradecimiento al soberano por su apoyo a esta empresa tan loable, sin mencionar ninguno de los puntos referidos por el condestable. El Consejo acordó que Carlos II se mostrase ante el nuncio a favor de la defensa de la Cristiandad, dejando entrever que se hallaba a la espera de que Su Santidad le remitiese los pormenores y la lista de los participantes ${ }^{30}$.

Aprovechando los preparativos que Carlos II se había visto obligado a ordenar en Milán por los movimientos del rey francés, el marqués del Carpio solicitó de nuevo una liga italiana bajo el pretexto antiturco. El pontífice, que se hallaba enojado por la escasa defensa organizada para defender el ducado milanés' le reiteró que no concurriría a una liga que ponía al Papado en el punto de mira del sultán y que le enemistaba con Luis XIV. En sus palabras se reflejó el enfado de un papa que estaba asistiendo a la decadencia de la posición internacional de la Santa Sede, a la que se recurría para solicitar asistencia al tiempo que se rechazaba su presencia en otros acontecimientos como la paz de Nimega (Caravale y Caracciolo, 1978: 435) ${ }^{31}$

En su intervención, había dejado claro que su objetivo no era el acuerdo anhelado por la Monarquía Hispánica, sino frenar la expansión del Imperio Otomano. De ahí su resentimiento ante la falta de asistencia de España al rey polaco. No había concedido la décima en Italia ni se vislumbraba intención alguna al respecto. El pontífice apremiaba a Carlos II a hacerlo si no quería encontrarse una Italia invadida por los otomanos y sin el apoyo papal, pues no le consentiría "emplear ni un escudo de las décimas para su defensa" ${ }^{2}$.

La Santa Sede reclamó durante todo el reinado de Carlos II el empleo adecuado de las contribuciones eclesiásticas para la defensa de la Cristiandad frente al "enemigo común". Conviene recordar que para financiar las distintas medidas defensivas se necesitaba que el pontífice renovase los ingresos de la cruzada, el subsidio y otras gracias concedidas a la Monarquía. El caso de la negociación de la cruzada resultó bastante compleja, porque la Santa Sede estaba al corriente del uso indebido del efecto por parte de Juan José de Austria. El hermanastro había percibido 120.000 escudos anuales provenientes de dicha partida. Estas prácticas motivaron la protesta de la Santa Sede, que en 1679 recordó a través

29 AGS, E, leg. 3.060, doc. "Tradución del Breve de Su Santidad escrito a Su Magestad a 19 de Marzo 1679".

30 AGS, E, leg. 3.060, docs. Madrid, 16-05-1679 y Madrid, 07-06-1679; leg. 3.061, doc. Madrid, 22-11-1679.

31 AGS, E, leg. 3.062, docs. Roma, 18-02-1680 y Madrid, 02-04-1680.

32 AGS, E, leg. 3.062, docs. Roma, 18-02-1680 y Madrid, 02-04-1680. 
de su nuncio en Madrid, que aquel ingreso estaba destinado al mantenimiento de sesenta galeras para la salvaguarda de las costas italianas frente al peligro otomano. Con la muerte de Juan José de Austria, se recuperó una parte de las rentas de las que gozaba y se impidió a sus familiares vincular diversos privilegios a las mismas (Marqués, 1982-1983: 55) ${ }^{33}$.

A pesar de ello, la intención del pontífice de renovar aquellas gracias pronto se esfumó, porque la noticia de que 10.000 escudos de los asignados a Juan José de Austria habían sido concedidos al marqués de Villafranca, que en aquellos momentos no estaba sirviendo en ningún puesto militar, generaron el enojo de Inocencio XI, que exigía una serie de condiciones para que se prorrogasen los efectos, que a finales de 1680, se incrementaron con el deseo papal de la retirada del marqués del Carpio. La Corona polaca continuaba esperando la ayuda española, porque la Monarquía Hispánica había aprobado destinar la mitad de las décimas al Sacro Imperio ${ }^{34}$.

No obstante, las gestiones del embajador dieron resultado y en julio de 1681, el nuncio notificaba la renovación del subsidio y del excusado, aclarando que se hacía por respeto al soberano español y no porque fuera lo más justo en ese caso. Se había constatado que no se empleaba en los fines pactados, por lo que se advertía que si continuaban las malas prácticas se revocaría su concesión. En cuanto a la prórroga de la cruzada, fue denegada porque el plazo no expiraba hasta 1691 (Marqués, 1982-1983: 57; Signorotto, 2007: 591) ${ }^{35}$.

\subsection{El fracaso de la Liga de Italia}

El fracaso de la liga llevaría a la Monarquía Hispánica a replantearse el envío de un embajador extraordinario a Roma, como sospechaba la Santa Sede que se haría. No andaba muy desencaminado el Papado porque poco después llegaba a Roma el nuevo agente, Francisco Bernardo de Quirós, que iniciaría su labor instando al pontífice a remediar las artimañas de Luis XIV para obstaculizar la asistencia al emperador en su guerra antiturca en Hungría. Según el papa, se estaba haciendo todo lo posible proponiéndole que luchara contra el "enemigo común" y no contra los cristianos ${ }^{36}$.

La noticia de los preparativos navales del monarca francés para enfrentarse a Génova provocó la alerta de la Corona. Aquel año, Luis XIV declaraba de nuevo la guerra y pidió a la República de Génova que ninguna de sus galeras navegase al servicio de la Monarquía ${ }^{37}$. Esta última decretó el traslado de la armada del Mar Océano al Mediterráneo para unirla a las escuadras de España, Nápoles, Sicilia, Cerdeña, así como a la genovesa del duque de Tursi. Además, se envió al duque de Giovenazzo, como embajador extraordinario para retomar las negociaciones de la liga de Italia ${ }^{38}$.

En los siguientes años, el contexto internacional hizo que las posturas de la Monarquía Hispánica y el Papado continuasen distanciadas. En marzo de 1684 se firmó la Liga Santa para la defensa de la Cristiandad frente a la amenaza del "enemigo común". El asedio de Viena en 1683 había propiciado el surgimiento de una Europa cristiana más unida, que

33 AGS, E, leg. 3.061, doc. Madrid, 10-08-1679.

34 BAV, Barb. lat. 6655, ff. 21-22.

35 AGS, E, leg. 3.195, doc. Madrid, 17-12-1680; leg. 3.064, doc. Roma, 16-03-1681; leg. 3.065, docs. Madrid, 02-07-1681 y Madrid, 08-07-1681.

36 AGS, E, leg. 3.066, doc. Madrid, 05-02-1682, leg. 3.068, docs. Roma, 20-12-1682, Madrid, 26-01-1683 y Madrid, 13-03-1683. Sobre Francisco Bernardo de Quirós, véase en Ozaman, 2009.

37 El incumplimiento del ultimátum francés de 1684 a la República de Génova provocó el bombardeo de la ciudad de Génova durante cinco días. Sin ayuda española, el dogo se vio obligado a pedir perdón a Luis XIV y a excusarse por su comportamiento. Véase Sella, 2003: 20.

38 AGS, E, leg. 3.069, docs. Roma, 04-07-1683, Roma, 04-07-1683 y Madrid, 13-08-1683. Sobre Domingo Giudice, duque de Giovenazzo, véase Andújar, 2009. 
seguía la idea papal de una "cruzada", convocada para reafirmar el liderazgo pontificio entre los cristianos y reunir una liga ofensiva y defensiva cristiana para reconquistar Constantinopla. Este proyecto logró la participación del Sacro Imperio, Polonia, Venecia y de Rusia, que se adhirió en 1686, bajo la égida del Papado. La política oriental desarrollada por algunos de los papas del siglo XVI, cuajó en esta confederación de potencias cristianas de la Europa oriental y occidental (Tamborra, 1961: 9; Menniti, 2000: 380-381; Rivero, 2008 : 26, 121 y $246-247)^{39}$.

Mientras tanto, España entró en la Liga de Augsburgo con el propósito de mantener la tregua pactada en Ratisbona, pero los deseos expansionistas de Luis XIV se volvieron a manifestar en la invasión de Colonia y el ataque al Palatinado con motivo de su sucesión en septiembre de 1688. Comenzaba así la Guerra de los Nueve Años (1688-1697), un conflicto en el que la Corona española centró sus esfuerzos en defender los territorios de Flandes, Italia y Cataluña, invadidos por Luis XIV (Kamen, 2000: 231-234; Rivero 2000: 151; Elliott, 1965: 405). Los intentos de acordar una Liga de Italia no se vieron interrumpidos por dicho conflicto. Durante los años siguientes los embajadores españoles en Roma mantendrían, aunque sin éxito, las negociaciones destinadas a conseguir dicho acuerdo, por lo que la búsqueda de una liga italiana no debe verse como un intento puntual del periodo de estudio de este artículo, ya que fueron varios los intentos que se sucedieron durante el reinado de Carlos II. El 17 de diciembre de 1699 hacía su entrada en Roma el duque de Uceda y al poco tiempo llegaba el aviso de la enfermedad de Inocencio XII. La urgencia del asunto obligó al nuevo embajador a reunirse con el cardenal Giudice para trazar la estrategia que se iba a desarrollar durante un futuro cónclave. Sin embargo, la Corona española estaba preocupada por la otra cuestión que concitaba la atención de las potencias europeas: la sucesión de Carlos II. En este sentido, el embajador tenía como misión averiguar la opinión de Inocencio XII respecto a dicha cuestión. Resultaba esencial lograr la alianza de la Santa Sede para poder mantener la presencia española en la península itálica. En las instrucciones se recordaban todos los intentos llevados a cabo desde 1674 por conseguir la creación de una liga de Italia, que todavía centraba el interés de la Monarquía. Debía buscar la estabilidad de Italia, manteniendo informada a la Corte de las intenciones de los potentados italianos ante una hipotética unión, pues podía ser favorable, pero también cabía la posibilidad de que fuese en contra de la Corona española (Martín, 2011: 50-51) ${ }^{40}$.

\section{CONCLUSIONES}

La Monarquía Hispánica tuvo que hacer frente durante el reinado de Carlos II a diversas contiendas contra la Corona francesa a la vez que vigilaba estrechamente los movimientos de la Sublime Puerta en el mar Mediterráneo. La relevancia adquirida por este gran mar interior en algunos de estos enfrentamientos, como la Guerra de Holanda, hizo que la política mediterránea de aquellos años continuara teniendo cierta importancia dentro de la política exterior de Carlos II, caracterizada igualmente por la labor de sus diplomáticos en la búsqueda constante de alianzas con el propósito de frenar los designios de Luis XIV.

En esta coyuntura internacional la Monarquía Hispánica intentó mantener una estable representación diplomática ante la Santa Sede para vigilar atentamente las relaciones de esta con la Corona de Francia, confirmándose sus temores con el estallido de la revuelta de Mesina, cuando el papa alegó su condición de Padre Común para justificar su decisión de no prestar su escuadra a la Monarquía. La negativa de promover la liga italiana que España

39 Para una visión más completa de los artículos de la Liga Santa de 1684 y la incorporación de Rusia en 1686, véase Jačov, 2001: 232-254.

40 AHN, E, leg. 1.813, doc. Madrid, 02-10-1699. 
pretendía crear contra Luis XIV terminó por enturbiar las relaciones entre ambas potencias, dirigiéndose desde entonces los esfuerzos españoles a incrementar su influencia y control en las decisiones pontificias frente al poder del monarca francés.

La diferencia de prioridades se fue acentuando con el tiempo siendo más evidente durante el pontificado de Inocencio XI, preocupado por obtener una paz duradera entre franceses y españoles cuyo principal objetivo debía ser la expulsión del gran turco de Europa. La diplomacia española fracasó continuamente a lo largo de estos años en su intento de obtener el apoyo de la Santa Sede a su liga italiana que el pontífice interpretó como un obstáculo a su política, pues podía suponer la enemistad de Luis XIV y, con ello, el fracaso de su mediación en una paz entre ambas monarquías. Firmada la paz de Nimega, el pontífice se concentró en reactivar el viejo ideal de "Cruzada" situando al Papado al frente de la Cristiandad en su intento de promover una coalición internacional contra el sultán, que fue finalmente suscrita con la Liga Santa de 1684. La ausencia de la Corona española en la Liga Santa y la falta de ayuda tanto logística como económica al emperador en su lucha antiturca, motivaron cierto empeoramiento de sus relaciones diplomáticas mientras continuó solicitando una liga italiana basada en su potencial terrestre y marítimo destinado a la defensa de sus propios dominios ante los designios del soberano galo.

En definitiva, durante los años de este estudio, el reinado de Carlos II se caracterizó por la labor de los diplomáticos españoles y los servicios de inteligencia de la Corona, quienes aportaron constantemente la información necesaria sobre los movimientos de Luis $\mathrm{XIV}$, con el propósito de tener preparadas las defensas de los dominios italianos. Asimismo, no debemos olvidar que aunque se malogró la propuesta de una liga italiana contra Francia, la labor de los embajadores españoles permitió vigilar atentamente los movimientos de los soberanos italianos evitando una liga de estos últimos con Luis XIV, al tiempo que consiguió mantener un cierto poder español ante la Santa Sede.

\section{BIBLIOGRAFÍA}

Alcalá-Zamora y Queipo de Llano, J. (1976): Razón de Estado y geoestrategia en la política italiana de Carlos II: Florencia y los Presidios (1677-1681), Boletín de la RAH, 173, pp. 297-358.

Andretta, S. (1998): Venezia e Roma dalla guerra di Candia a Clemente XI, en Signorotto, G. y Visceglia, M. A. (eds.), La Corte di Roma tra Cinque e Seicento "teatro" della politica europea, Roma, Bulzoni, pp. 393-422.

Barrio Gozalo, M. (2009): "La embajada de España ante la Corte de Roma en el siglo XVII. Ceremonial y práctica del buen gobierno", Studia Historica. Historia Moderna, 31, pp. 237-273.

- (2013): La embajada de España en Roma durante el reinado de Carlos II (1665-1700), Valladolid, Universidad de Valladolid.

Caravale, M. y Caracciolo, A. (1978): Lo Stato pontificio da Martino V a Pio IX, Torino, UTET. Dandelet, T. J. (2002): La Roma española (1500-1700), Barcelona, Crítica.

Elliott, J. H. (1965): La España Imperial, 1469-1716, Barcelona, Vicens Vives.

Feldkamp, M. F. (2004): La diplomacia pontificia. Desde el papa Silvestre hasta Juan Pablo II, Madrid, BAC.

Fernández Nadal, C. M. (2009): La política exterior de la monarquía de Carlos II. El Consejo de Estado y la embajada de Londres (1665-1700), Gijón, Ateneo Jovellanos.

González Cuerva, R. (2012): La última cruzada: España en la guerra de la Liga Santa (16831699), en Sanz Camañes, P. (ed.), Tiempo de cambios. Guerra, diplomacia y política internacional de la Monarquía Hispánica (1648-1700), Madrid, Actas, pp. 221-248.

Herrero Sánchez, M. (2000): El acercamiento hispano-neerlandés (1648-1678), Madrid, 
CSIC.

- (2009): "Haro y Guzmán, Gaspar de", en Diccionario Biográfico Español, Madrid, RAH, pp, 582-586.

Jačov, M. (2001): L' Europa tra conquiste ottomane e leghe sante, Città del Vaticano, Biblioteca Apostolica Vaticana.

Kamen, H. (2000): "España en la Europa de Luis XIV", en Menéndez Pidal, R. y Jover Zamora, J. M., Historia de España, Madrid, Espasa, vol. XXXVIII, pp. 205-298.

Marqués, J. M. (1982-1983): La Santa Sede y la España de Carlos II. La negociación del nuncio Millini (1675-1685), Roma, Iglesia Nacional de España.

Martín Marcos, D. (2011): El Papado y la Guerra de Sucesión Española (1697-1717), Madrid, Marcial Pons.

Martínez Millán, J. (2010): "El triunfo de Roma. Las relaciones entre el Papado y la Monarquía durante el siglo XVII", en Martínez Millán, J. y Rivero Rodríguez, M. (coord.), Centros de Poder Italianos en la Monarquía Hispánica (siglos XV-XVII), Madrid, Polifemo, pp. 549-681.

Mesa Coronado, M. P. (2014): "La isla de Candía en la diplomacia Hispano-Veneciana (1665-1669)", Investigaciones Históricas, 34, pp. 81-105.

- (2017): La política italiana de Carlos II: las instrucciones a los embajadores en Roma, en Martínez Millán, J., Labrador Arroyo, F. y Valido-Viegas de Paula-Soares, F. M. (dirs.), ¿Decadencia o reconfiguración? Las Monarquías de España y Portugal en el cambio de siglo (1640-1724), Madrid, Polifemo, pp. 255-274.

Menniti Ippolito, A. (2000): Innocenzo XI, en Enciclopedia dei Papi. Roma, vol. III, pp. 368389.

Mitchell, S. (2016): "Marriage plots: royal women, marriage diplomacy and international politics at the Spanish, French and Imperial Courts, 1665-1679", en Sluga, G. y James, C. (eds.), Women, diplomacy and international politics since 1500, New York, Routledge, 86-106.

- (2019): Queen, mother and stateswoman: Mariana of Austria and the government of Spain, Pennsylvania, The Pennsylvania State University Press.

Ochoa Brun, M. A. (2006): Historia de la diplomacia española, Madrid, Ministerio de Asuntos Exteriores y de Cooperación, vol. II.

Osbat, L. (2000): "Clemente X”, en Enciclopedia dei papi, Roma, vol. III, pp. 360-368.

Ozaman, D. (2009): "Bernardo de Quirós y Valdés, Francisco", en Diccionario Biográfico Español. Madrid, RAH, vol. VIII, pp. 193-194.

Palacios Ontalva, S. (2015): "Cruzada y cruzadas. Un fenómeno medieval proyectado hacia el futuro", en García Martín, P., Quirós Rosado, R. y Bravo Lozano, C., Antemurales de la Fe. Conflictividad confesional en la Monarquía de los Habsburgo, 1516-1714, Madrid, Ministerio de Defensa, pp. 19-36.

Peña Izquierdo, A. R. (2004): La Casa de Palma. La Familia Portocarrero en el Gobierno de la Monarquía Hispánica (1665-1700), Córdoba, Universidad de Córdoba.

Platania, G. (1998): Innocent XI Odescalchi et l'esprit de 'Crosaide', en Revue XVII' Siècle, 199, 50e année, núm. 2, pp. 247-276.

Poncet, O. (2011): La France et le pouvoir pontificial (1595-1661): l'esprit des institutions, Rome, École française de Rome.

Poumarède, G. (2011): Il Mediterraneo oltre le crociate. La guerra turca nel Cinquecento e nel Seicento tra leggende e realtà, Torino, UTET.

Quiles Albero, D. (2018): Las relaciones hispano-venecianas en el contexto de la guerra de Candía (1645-1669), Chronica Nova, 44, pp. 381-406.

Ramírez de Villa-Urrutia, Marqués de Villa-Urrutia, W. (1927): La embajada del Marqués de Cogulludo a Roma en 1687 y el Duque de Medinaceli y la Giorgina, Madrid, Francisco Beltrán. 
Ribot García, L. A. (1982): La revuelta antiespañola de Mesina. Causas y antecedentes (1591-1674), Valladolid, Universidad de Valladolid.

- (2002): La Monarquía de España y la guerra de Mesina (1674-1678), Madrid, Actas.

Rivero Rodríguez, M. (2000): Diplomacia y relaciones exteriores en la Edad Moderna, 14531794, Madrid, Alianza Editorial.

- (2008): La batalla de Lepanto. Cruzada, guerra santa e identidad confesional, Madrid, Sílex.

Salvador Esteban, E. (2004): "La quiebra de la hegemonía hispánica. Un proceso complejo", en Aranda Pérez, A. (coord.), La declinación de la Monarquía Hispánica en el siglo XVII, Cuenca, Universidad de Castilla-La Mancha, vol. I, pp. 221-245.

Sánchez Belén, J. A. (1999): "Las relaciones internacionales de la Monarquía Hispánica durante la regencia de doña Mariana de Austria", Studia Historica. Historia Moderna, 20, pp. 137-172.

Sanz Ayán, C. (2009): "Fernández Portocarrero y Guzmán, Luis Manuel”, en Diccionario Biográfico Español, Madrid, RAH, vol. XIX, pp. 404-407.

Sella, D. (2003): L'Italia del Seicento, Roma, Laterza.

Signorotto, G. (2007): "Sui rapporti tra Roma, Stati italiani e Monarchia Cattolica in "età spagnola", en Hernando Sánchez, C. J. (coord.), Roma y España. Un crisol de la cultura europea en la Edad Moderna, Madrid, Sociedad Estatal para la Acción Cultural Exterior, vol. I., pp. 577-592.

Storrs, C. (2012): "La diplomacia espalola durante el reinado de Carlos II: una Edad de Oro o ¿quizá de Plata?", en Sanz Camañes, P. (ed), Tiempo de cambios. Guerra, diplomacia y política internacional de la Monarquía Hispánica (1648-1700), Madrid, Actas, pp. 21-53.

Tamborra, A. (1961): Gli stati italiani, l'Europa e il problema turco dopo Lepanto, Firenze, Leo S. Olschki.

Visceglia, M. A. (2004): "Convergencias y conflictos. La Monarquía Católica y la Santa Sede (siglos XV-XVIII)", Studia Histórica. Historia Moderna, 26, pp. 155-190.

-- (2010): Roma papale e Spagna: diplomatici, nobili e religiosi tra due corti, Roma, Bulzoni. Yétano Rodríguez, I. (2009): Relaciones entre España y Francia desde la Paz de los Pirineos (1659) hasta la Guerra de Devolución (1667). La embajada del marqués de la Fuente, Madrid, Fundación Universitaria Española.

Zamora Rodríguez, F. (2013): La 'Pupilla dell'Occhio della Toscana' y la posición hispánica en el Mediterráneo Occidental (1677-1717), Madrid, FEHM. 